\title{
Cardiomyocytes can be generated from marrow stromal cells in vitro
}

\author{
Shinji Makino, ${ }^{1}$ Keiichi Fukuda, ${ }^{1}$ Shunichirou Miyoshi, ${ }^{1}$ Fusako Konishi, ${ }^{1}$ \\ Hiroaki Kodama, ${ }^{1}$ Jing Pan, ${ }^{1}$ Motoaki Sano, ${ }^{1}$ Toshiyuki Takahashi, ${ }^{1}$ Shingo Hori,${ }^{1}$ \\ Hitoshi Abe, ${ }^{2}$ Jun-ichi Hata, ${ }^{2}$ Akihiro Umezawa, ${ }^{2}$ and Satoshi Ogawa ${ }^{1}$ \\ ${ }^{1}$ Cardiopulmonary Division, Department of Internal Medicine, and \\ ${ }^{2}$ Department of Pathology, Keio University School of Medicine, Tokyo 160-8582, Japan \\ Address correspondence to: Keiichi Fukuda, Molecular Cardiology Unit, Cardiopulmonary Division, \\ Department of Internal Medicine, Keio University, 35 Shinanomachi, Shinjuku-ku, Tokyo 160-8582, Japan. \\ Phone: 81-3-3353-1211, ext. 2310; Fax: 81-3-5269-3678; E-mail:kfukuda@mc.med.keio.ac.jp
}

Received for publication September 21, 1998, and accepted in revised form January 18, 1999.

\begin{abstract}
We have isolated a cardiomyogenic cell line (CMG) from murine bone marrow stromal cells. Stromal cells were immortalized, treated with 5-azacytidine, and spontaneously beating cells were repeatedly screened. The cells showed a fibroblast-like morphology, but the morphology changed after 5-azacytidine treatment in $\sim 30 \%$ of the cells; they connected with adjoining cells after one week, formed myotube-like structures, began spontaneously beating after two weeks, and beat synchronously after three weeks. They expressed atrial natriuretic peptide and brain natriuretic peptide and were stained with anti-myosin, anti-desmin, and anti-actinin antibodies. Electron microscopy revealed a cardiomyocyte-like ultrastructure, including typical sarcomeres, a centrally positioned nucleus, and atrial granules. These cells had several types of action potentials, such as sinus node-like and ventricular cell-like action potentials. All cells had a long action potential duration or plateau, a relatively shallow resting membrane potential, and a pacemaker-like late diastolic slow depolarization. Analysis of the isoform of contractile protein genes, such as myosin heavy chain, myosin light chain, and $\alpha$-actin, indicated that their muscle phenotype was similar to that of fetal ventricular cardiomyocytes. These cells expressed Nkx2.5/Csx, GATA4, TEF-1, and MEF-2C mRNA before 5-azacytidine treatment and expressed MEF-2A and MEF-2D after treatment. This new cell line provides a powerful model for the study of cardiomyocyte differentiation.
\end{abstract}

J. Clin. Invest. 103:697-705 (1999)

\section{Introduction}

Although significant progress has been made in the molecular understanding of skeletal muscle growth and differentiation $(1,2)$, little is known about the genes involved in heart development (3). A number of skeletal muscle cell lines have been established (4-6) in which myoblasts can not only regenerate but also differentiate into myotubes. The isolation and extensive characterization of the MyoD gene family were performed using these cell lines (7-9), and these cells have brought significant progress to our molecular understanding of skeletal muscle differentiation (10). The isolation of a cardiomyogenic cell line (CMG) that may facilitate the molecular analysis of cardiomyocyte development has been long awaited (11).

Myocardial infarction is a leading cause of morbidity and mortality in civilized countries. Cardiomyocytes do not regenerate after birth, and they respond to mitotic signals by cell hypertrophy $(12,13)$ rather than by cell hyperplasia. Loss of cardiomyocytes leads to regional contractile dysfunction, and necrotized cardiomyocytes in infarcted ventricular tissues are progressively replaced by fibroblasts to form scar tissues. Recent studies revealed that transplanted fetal cardiomyocytes could survive in this heart scar tissue (14) and that these transplanted cells limited scar expansion and prevented postinfarction heart failure. The transplantation of cultured cardiomyocytes into the damaged myocardium has been proposed as a future method for the treatment of heart failure (15-17). Although this is a revolutionary idea, it remains infeasible in the clinical setting because it is difficult to obtain donor fetal heart. A CMG cell line could potentially substitute for fetal cardiomyocytes in this therapy. Therefore, both developmental biologists and cardiologists eagerly await the development of a CMG cell line.

Recent reports (18-23) have revealed that marrow stromal cells have many characteristics of mesenchymal stem cells. Pluripotential progenitor marrow stromal cells may differentiate into various types of cell types, including bone $(19,20)$, muscle (21), fat (22), tendon, or cartilage (23). On the basis of these findings, we hypothesized that marrow stromal cells might also differentiate into cardiomyocytes. We therefore repeatedly screened marrow stromal cells that began spontaneously beating after exposure to 5-azacytidine, a cytosine analog capable of altering expression of certain genes that may regulate differentiation. To our knowledge, this is the first report of the establishment of a cell line that differentiates into cardiomyocytes in vitro from adult marrow stromal cells. The cells were characterized electrophysiologically and ultrastructurally and were examined for cardiomyocyte-specific gene expression. The use of adult 
Table 1

PCR primers used in this study

\begin{tabular}{|c|c|c|}
\hline & Sense & Anti-sense \\
\hline ANP & 5'-TTGGCTTCCAGGCCATAATTG-3' & 5'-AAGAGGGCAGATCTATCGGA-3' \\
\hline BNP & 5'-ATGGATCTCCTGAAGGTGCT-3' & 5'-AAGAGGGCAGATCTATCGGA-3' \\
\hline$\alpha-\mathrm{MHC}$ & 5'-GGAAGAGTGAGCGGCCATCAAGG-3' & 5'-CTGCTGGAGAGGTTATTCCTCG-3' \\
\hline$\beta-\mathrm{MHC}$ & 5'-GCCAACACCAАCCTGTCCAAGTTC-3' & 5'-TGCAAAGGCTCCAGGTCTGAGGGC-3 \\
\hline$\alpha$-skeletal actin & 5'-СтСТСтСтССтCAGGACAA-3' & 5'-TGGAGCAAAACAGAATGGCTGG-3' \\
\hline$\alpha$-cardiac actin & 5'-СTGAGATGTCTCTCTCTCTCTTAG-3' & 5'-ACAATGACTGATGAGAGATG-3' \\
\hline MLC-2a & 5'-CAGACCTGAAGGAGACCT-3' & 5'-GTCAGCGTAAACAGTTGC-3' \\
\hline MLC-2v & 5'-GCCAAGAAGCGGATAGAAGG-3' & 5'-CTGTGGTTCAGGGCTCAGTC-3' \\
\hline Nkx2.5/Csx & 5'-CAGTGGAGCTGGACAAAGCC-3' & 5'-TAGCGACGGTTCTGGAACCA-3' \\
\hline GATA4 & 5'-CTGTCATCTCACTATGGGCA-3' & 5'-CCAAGTCCGAGCAGGAATTT-3' \\
\hline TEF-1 & 5'-AAGACGTCAAGCCCTTTGTG-3' & 5'-AAAGGAGCACACTTTGGTGG-3' \\
\hline MEF-2C & 5'-AGCAAGAATACGATGCCATC-3' & 5'-GAAGGGGTGGTGGTACGGTC-3' \\
\hline MEF-2D & 5'-TGGGAATGGCTATGTCAGTG-3' & 5'-CTGGTAATCTGTGTTGTAGG-3' \\
\hline
\end{tabular}

$A N P$, atrial natriuretic peptide; $B N P$, brain natriuretic peptide; $M E F$, muscle enhancement factor; $M H C$, myosin heavy chain; $M L C$, myosin light chain.

tissues as a source of cardiomyocytes makes this system particularly appropriate for the development of gene therapy strategies for heart disease.

\section{Methods}

Cell culture. Female $\mathrm{C} 3 \mathrm{H} / \mathrm{He}$ mice $(n=10)$ were anesthetized with ether, thigh bones were excised, and bone marrow cells were obtained. The procedures were performed in accordance with the guidelines for animal experimentation of Keio University. Primary culture of the marrow cells was performed according to Dexter's method (24). Cells were cultured in Iscove's modified Dulbecco's medium (IMDM) supplemented with $20 \%$ FBS and penicillin $(100 \mu \mathrm{g} / \mathrm{ml}) /$ streptomycin $(250 \mathrm{ng} / \mathrm{ml}) /$ amphotericin $\mathrm{B}(85 \mu \mathrm{g} / \mathrm{ml})$ at $33^{\circ} \mathrm{C}$ in humid air with $5 \% \mathrm{CO}_{2}$. After a series of passages, attached marrow stromal cells became homogeneous and were devoid of hematopoietic cells. The marrow stromal cells basically did not require coculture of blood stem cells. Immortalized cells were obtained by frequent subculture for more than 4 months. Cell lines from different dishes were subcloned by limiting dilution. To induce cell differentiation, cells were treated with $3 \mu \mathrm{mol} / 1$ of 5 -azacytidine (Sigma Chemical Co., St. Louis, Missouri, USA) for $24 \mathrm{~h}$. Subclones that included spontaneously beating cells were screened by microscopic observation (first screening), and cells surrounding spontaneously beating cells were subcloned by cloning syringes. Subcloned cells were maintained and again exposed to 5-azacytidine for $24 \mathrm{~h}$, and clones that showed spontaneous beating most frequently were screened (second screening). The screened clone was named the CMG (cardiomyogenic) cell.

Videotape recording. The cultured cells were observed through an inverted-type phase-contrast video microscope (TMD300; Nikon, Tokyo, Japan) equipped with a $40 \times$ quartz objective lens and an $8 \times$ relay lens. The culture dish was kept at $33^{\circ} \mathrm{C}$ using a temperature-controlled closed chamber. The cell images were introduced into an intensified charged couple device camera (KPC251; Hitachi Denshi/Sankei, Tokoyo, Japan) and videotaped by an sVHS recorder (VZ-470; Sanyo, Tokyo, Japan). A gray density filter (ND16; Nikon) was used to limit unnecessary light exposure to epi-illumination by a xenon lamp $(100 \mathrm{~W})$. Image processing software (NIH Image 1.59/Power Macintosh 7200; National Institutes of Health, Bethesda, Maryland, USA) was used to determine alterations in the size of cells.

Immunostaining. A monoclonal antibody (MF20) to sarcomeric myosin was obtained from American Type Culture Collection (Rockville, Maryland, USA). A monoclonal antibody to desmin was purchased from Bio-Science Products
(Emmenbrücke, Switzerland), and a monoclonal antibody to actinin was purchased from Sigma Chemical Co. Cells grown on glass coverslips were permeabilized in $1 \%$ formaldehyde/PBS for $10 \mathrm{~min}$. After blocking with 5\% BSA in PBS for $1 \mathrm{~h}$ at room temperature, the cells were incubated with primary antibodies. After three washes in PBS for 5 min each, the biotinylated/conjugated anti-mouse IgG (DAKO Corp., Carpinteria, California, USA) was applied for $30 \mathrm{~min}$ at a dilution of 1:400. Visualization was achieved through the streptavidin-biotin horseradish peroxidase detection system.

Transmission electron microscopy. For transmission electron microscopy of cultured cells, cells were washed three times with PBS ( $\mathrm{pH}$ 7.4). The initial fixation was done in PBS containing $2.5 \%$ glutaraldehyde for $2 \mathrm{~h}$. The cells were embedded in epoxy resin. Ultrathin sections cut horizontally to the growing surface were double stained in uranyl acetate and lead citrate and were viewed under a JEM-1200EX transmission electron microscope (Nihon Denshi, Tokyo, Japan).

Action potential recording. Electrophysiological studies were performed in IMDM containing (in mmol/l) $\mathrm{CaCl}_{2} 1.49, \mathrm{KCl} 4.23$, and HEPES 25 (pH 7.4). Cultured cells were placed on the stage of an inverted phase-contrast optic (Diaphoto-300; Nikon) at room temperature $\left(25^{\circ} \mathrm{C}\right)$. Action potentials were recorded by conventional microelectrode. Intracellular recordings were made from 2- to 5-week-old cultured cells with a distinguishable phenotype. Glass microelectrodes filled with $\mathrm{KCl}$ ( $3 \mathrm{~mol} / \mathrm{l})$ having a DC resistance of $15-30 \mathrm{M} \Omega$ were selected. Membrane potentials were measured by means of current clamp mode (MEZ-8300; Nihon Kohden, Tokyo, Japan) with a built-in fourpole Bessel filter set at $1 \mathrm{kHz}$. The data were recorded on the thermal recorder (RTA-1100M; Nihon Kohden) and stored on a digital magnetic tape (frequency range $0-20 \mathrm{kHz}$, Sony Magnescale; Sony Co., Tokyo, Japan) for later analysis.

$R N A$ extraction, reverse transcriptase-PCR, and Southern blot analysis. Total RNA was extracted from adult mouse heart, skeletal muscle, and differentiated CMG cells by Trizol Reagent (GIBCO BRL, Gaithersburg, Maryland, USA). Reverse transcriptase (RT)-PCR of cardiomyocyte-specific genes, including atrial natriuretic peptide (ANP; ref. 25), brain natriuretic peptide (BNP; ref. 26), $\alpha$ - and $\beta$-myosin heavy chain ( $\alpha$ and $\beta$-MHC; ref. 27), $\alpha$-skeletal actin, $\alpha$-cardiac actin, myosin light chain-2a and $-2 \mathrm{v}$ (MLC-2a and $-2 \mathrm{v}$; ref. 28), Nkx2.5/Csx $(29,30)$, GATA4 (31), TEF-1 (32), MEF-2A, -2C, and -2D (Morisaki, T., personal communication), was performed using $1 \mu \mathrm{g}$ of total RNA. DNase I was applied at $23^{\circ} \mathrm{C}$ for $15 \mathrm{~min}$. PCR was performed for 30-35 cycles, with each cycle consist- 

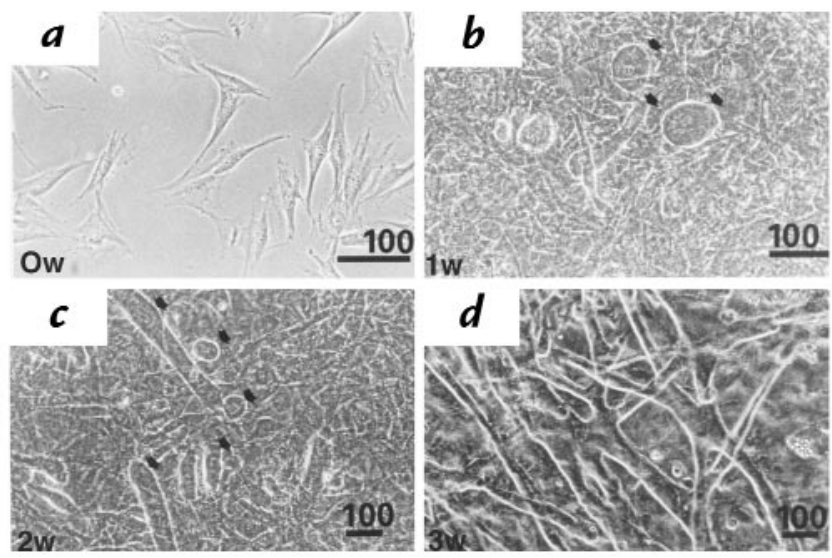

Figure 1

Phase-contrast photographs of CMG cells before and after 5-azacytidine treatment. (a) CMG cells show fibroblast-like morphology before 5-azacytidine treatment ( 0 weeks, OW). (b) One week after treatment. Some cells gradually increased in size and formed a ball-like or stick-like appearance (arrowheads). These cells began spontaneously beating thereafter. (c) Two weeks after treatment. Ball-like or stick-like cells connected with adjoining cells and began to form myotube-like structures. (d) Three weeks after treatment. Most of the beating cells were connected and formed myotube-like structures. Scale bars: $100 \mu \mathrm{m}$. CMG, cardiomyogenic cell line.

ing of $95^{\circ} \mathrm{C}$ for $30 \mathrm{~s}, 53-60^{\circ} \mathrm{C}$ for $1.5 \mathrm{~min}$, and $72^{\circ} \mathrm{C}$ for 1 min, with an additional 7 -min incubation at $72^{\circ} \mathrm{C}$ after completion of the last cycle. The primers used are described in Table 1 . The PCR products were size-fractionated by $3 \% \mathrm{Nu}$ Sieve agarose gel electrophoresis. In some experiments, the gels were transferred to nylon membranes (Hybond N), and ultraviolet cross-linked. The Southern blot hybridization was performed at $42^{\circ} \mathrm{C}$ for $24 \mathrm{~h}$ using a ${ }^{32} \mathrm{P}$ end-labeled internal 25 -bp fragment. The internal 25 -bp fragments used were as follows: ANP, CTGAGTGAGCAGACTGAGGAAGCAG; BNP, AAAAGTCGGAGGAAATGGCCCAGAG; Nkx2.5 /Csx, TTCAAGCAACAGCGGTACCTGT; GATA4, TGACAGTCATGGGGACATAATCACC; TEF-1, TTGAACAGCAGAGAGACCCAGA. Southern blots were washed several times with a final wash at $55^{\circ} \mathrm{C}$ in $2 \times \mathrm{SSC}(150 \mathrm{mmol} / 1 \mathrm{NaCl}, 15 \mathrm{mmol} / 1$ sodium citrate) containing $0.1 \%$ SDS for $30 \mathrm{~min}$. After washing, $\mathrm{x}$-ray film was exposed to the filter at $-70^{\circ} \mathrm{C}$.

Northern blot analysis was used for detection of $\alpha$-skeletal actin and $\alpha$-cardiac actin expression. Total RNA (20 $\mu$ g) was separated on a $1 \%$ MOPS/formaldehyde-agarose gel and blotted onto a nylon membrane (Hybond N). cDNAs for $\alpha$-skeletal actin and $\alpha$-cardiac actin were obtained by RT-PCR from mouse heart RNA and were cloned into pCR II plasmid. All cDNAs were confirmed by sequencing. Inserts were labeled by random priming with $\left[{ }^{32} \mathrm{P}\right] \mathrm{dCTP}$ (Du Pont NEN Research Products, Boston, Massachusetts, USA). After transfer, the blots were immersed in a Rapid-hyb buffer (Amersham Life Sciences Inc., Arlington Heights, Illinois, USA), and hybridization was performed according to the manufacturer's instructions. Blots were washed serially with a final wash at $55^{\circ} \mathrm{C}-65^{\circ} \mathrm{C}$ in $0.1 \times$ SSC containing $0.1 \%$ SDS for $30 \mathrm{~min}$.

\section{Results}

CMG cells form myotubes and show spontaneous contraction. We repeated limiting dilutions several times and isolated 192 single clones; however, we observed several clones that could differentiate into the cardiomyocytes and show spontaneous beating. These experi- ments were repeated and reproducible, but the percentage of cardiomyocyte differentiation was distinct among these clones.

To determine the morphological changes in CMG cells induced by 5 -azacytidine treatment, phase-contrast photography and/or immunostaining with anti-sarcomeric myosin, anti-actinin, and anti-desmin antibodies were performed on CMG cells. Figure 1 is a phase-contrast photograph of CMG cells before and after 5-azacytidine treatment. CMG cells showed a fibroblast-like morphology before 5-azacytidine treatment ( 0 week), and this phenotype was retained through repeated subcultures under nonstimulating conditions. After 5-azacytidine treatment, the morphology of the cells gradually changed. Approximately $30 \%$ of the CMG cells gradually increased in size, formed a ball-like appearance, or lengthened in one direction and formed a stick-like morphology at one week. They connected with adjoining cells after two weeks and formed myotube-like structures at three weeks. After the CMG cells differentiated to the cardiomyocytes, they could divide in culture to some extent. The differentiated CMG myotubes maintained cardiomyocyte phenotype and beat vigorously for at least eight weeks after final 5-azacytidine treatment, and they did not dedifferentiate. Most of the other nonmyocytes showed an adipocyte-like appearance.

Figure 2 shows the immunostaining of the CMG cells with anti-sarcomeric myosin antibody (MF20) at one, two, three, and four weeks after 5-azacytidine treatment. Myosin-positive cells gradually joined with neighboring myosin-positive cells and formed a myotube-like appearance. The maximum length of the myotubes ranged from $1,000 \mu \mathrm{m}$ to $3,000 \mu \mathrm{m}$. Cardiac muscle cells can be distinguished from skeletal muscle cells by the presence of branching fibers, and the CMG myotubes showed a number of branches. Figure 3 shows high magnification of the immunostaining of the differentiated CMG myotubes at four weeks with anti-myosin, anti-actinin, and anti-desmin antibodies. Most of the cells were
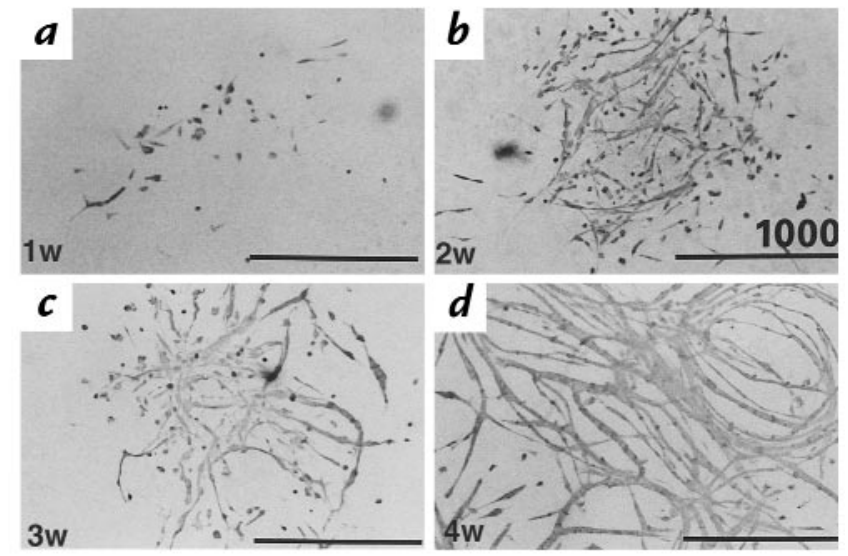

Figure 2

Immunostaining of CMG cells with anti-sarcomeric myosin antibody at 1 week $(\boldsymbol{a}), 2$ weeks $(\boldsymbol{b}), 3$ weeks $(\boldsymbol{c})$, and 4 weeks $(\boldsymbol{d})$ after 5 -azacytidine treatment. Myosin-positive cells could be observed at 1 week after 5 -azacytidine treatment. Myosin-positive cells gradually joined to neighboring myosin-positive cells and formed myotube-like structures. Scale bars: $1,000 \mu \mathrm{m}$. The maximal length of the myotube was 3,000 $\mu \mathrm{m}$. 

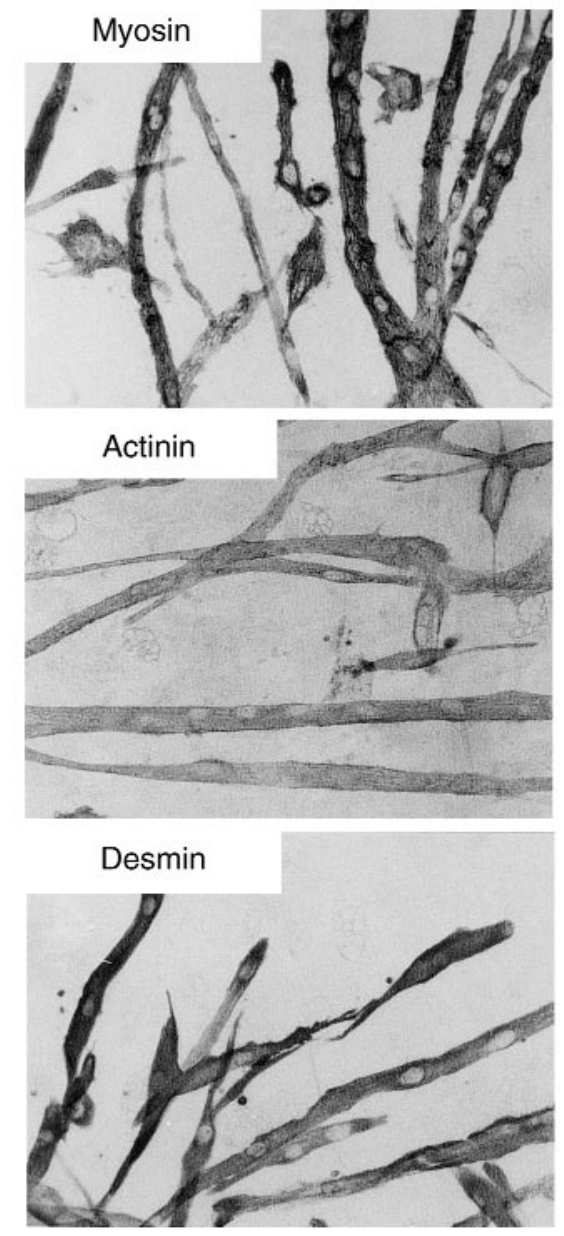

Figure 3

Immunostaining of CMG cells with anti-sarcomeric myosin, anti-actinin, and anti-desmin antibodies after 5 -azacytidine treatment ( 3 weeks). CMG myotubes were stained with both anti-sarcomeric myosin, antiactinin, and anti-desmin antibodies.

mononuclear, some were binuclear, but a few were multinucleated (3-10 per cell). Cells were connected to each other via intercalated discs and formed myotubes. CMG myotubes also stained strongly with anti-actinin and anti-desmin antibodies.

Figure 4 shows sequential photographs of the CMG myotubes obtained from a videotape recording that represents one contraction. Differentiated CMG myotubes showed repeated spontaneous contraction and relaxation without any stimulation. Spontaneous beating was also observed in isolated CMG cells. Myotubes began spontaneously beating after two weeks and beat synchronously after three weeks. The contractions were rapid and automatic-very different from those of smooth muscle cells and skeletal muscle cells in culture. The frequency of contractions ranged from 63 to 428 per minute.

CMG cells have a cardiomyocyte-like ultrastructure. Representative transmission electron microscopy photographs are shown in Fig. 5. Immature CMG cells at one to two weeks after treatment showed myofilaments, but their alignment was intricate (data not shown). However, a longitudinal section of the differentiated CMG myotubes clearly revealed the typical striation and palestaining pattern of the sarcomeres (Fig. 5a). CMG myotube nuclei were positioned in the center of the cell, not beneath the sarcolemma. The most conspicuous feature of the differentiated CMG myotubes was the presence of membrane-bound dense secretory granules measuring $70-130 \mathrm{~nm}$ in diameter (Fig. $5 b$ ). These granules were thought to be atrial granules and were especially concentrated in the juxtanuclear cytoplasm, but some were also located near the sarcolemma. These findings indicated that CMG cells had a cardiomyocyte-like, rather than skeletal muscle, ultrastructure.

CMG myotubes have several types of action potential. An electrophysiological study was performed on differentiated CMG cells at two to five weeks after 5-azacytidine treatment. There were at least two types of distinguishable morphological action potentials: sinus node-like potentials (Fig. 6a) and ventricular myocyte-like potentials (Fig. $6 b$ ). The sinus node-like action potential showed a relative shallow resting membrane potential with late diastolic slow depolarization, like a pacemaker potential. Peak- and domelike morphology were observed in ventricular myocyte-like cells. Table 2 gives the action potentials recorded in CMG myotubes. A cardiomyocyte-like action potential recorded from these spontaneously beating cells had the following properties: (a) a relatively long action potential duration or plateau $(b)$ a relatively shallow resting membrane potential, and $(c)$ a pacemaker-like late diastolic slow depolarization. Figure 7 shows a time course of the percentage of the sinus node-like and ventricular myocyte-like action potentials of the CMG cells after 5-azacytidine treatment. All the action potentials recorded from the CMG cells until three weeks revealed sinus node-like action potential. The ventricular myocyte-like action potentials could be recorded after four weeks, and the percentage of these action potentials gradually increased thereafter. It is possible that the percentage of the ventricular myocyte-like action potentials at five weeks was underestimated. Most of the action potentials recorded from differentiated CMG myotubes revealed ventricular myocyte-like appearance, but the action potential of the differentiated CMG myotubes was difficult to record. The glass microelectrode was frequently damaged because the spontaneous contraction of the differentiated myotube at five weeks was too big.

Cardiomyocyte-specific gene expression. Figure 8 shows RTPCR or Northern blot analysis of the expression of cardiomyocyte-specific genes in differentiated CMG cells. Figure $7 a$ represents an RT-PCR Southern blot using ANP and BNP gene probes. Total RNA obtained from

\section{Table 2}

Measurement of action potentials recorded in CMG myotubes

\begin{tabular}{lccccc}
\hline & $\mathrm{BCL}(\mathrm{ms})$ & $\mathrm{APD}(\mathrm{ms})$ & $\operatorname{MDP}(\mathrm{mV})$ & $\mathrm{APA}(\mathrm{mV})$ & $n$ \\
Sinus node-like cell & $143-788$ & $46.6 \pm 15.5$ & $-54.8 \pm 9.4$ & $58.5 \pm 14.6$ & 40 \\
Ventricular-like cell & $108-950$ & $58.2 \pm 14.1$ & $-59.5 \pm 7.8$ & $71.0 \pm 13.2$ & 18
\end{tabular}

$A P A$, action potential amplitude; $A P D$, action potential duration; $B C L$, beating cycle length; $M D P$, most diastolic membrane potential. 


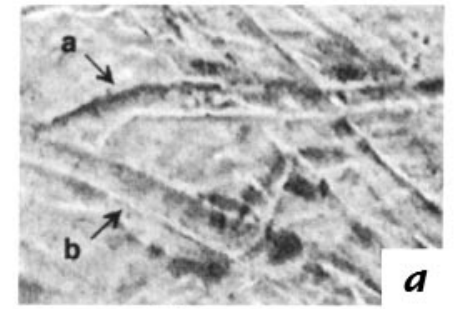

Time $=0$

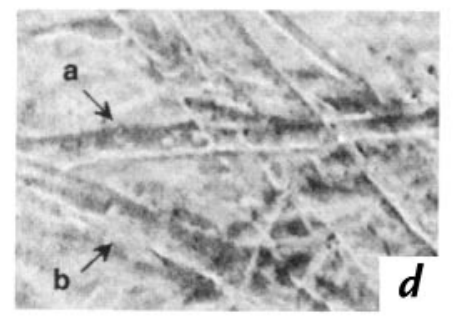

133

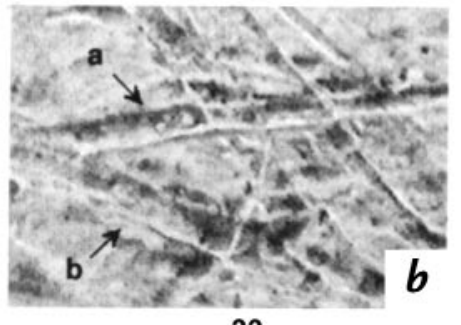

33

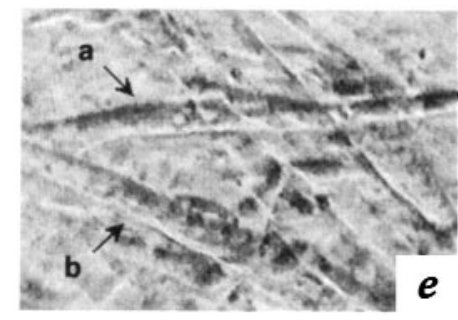

167

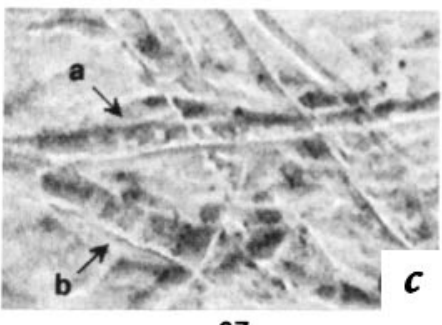

67

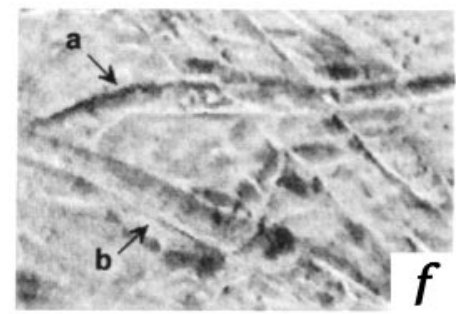

$200(\mathrm{~ms})$

Figure 4

A series of photographs representing one contraction of beating CMG myotubes recorded by phase-contrast video microscope. The beating differentiated CMG myotubes were videotaped as described in Methods. In each panel, $a$ and $b$ represent branches of a single myotube that beat spontaneously. Panel $\boldsymbol{a}$ is at the end of relaxation and panel $\boldsymbol{b}$ is at maximum contraction.

cardiomyocytes (in vivo heart) and skeletal muscles (soleus muscle) were used as positive and negative controls, respectively. Differentiated CMG myotubes expressed both the ANP and BNP genes. Figure $8 b$ shows the expression of the $\alpha$ - and $\beta$-MHC, $\alpha$-cardiac and $\alpha$ skeletal actin genes. Both $\alpha$ - and $\beta$-MHC expression could be detected by RT-PCR in differentiated CMG cells, but $\beta$-MHC expression was overwhelmingly stronger than that of $\alpha-M H C$. CMG cells expressed both $\alpha$-cardiac and $\alpha$-skeletal actin. Figure $8 c$ shows the Northern blot analysis of $\alpha$-cardiac and $\alpha$-skeletal actin gene expression. Adult mouse heart was used as a positive control. The $\alpha$-skeletal actin gene was expressed at markedly higher levels than the $\alpha$-cardiac actin gene in CMG cells. Interestingly, CMG cells expressed MLC-2v, but not MLC-2a (Fig. 8d).

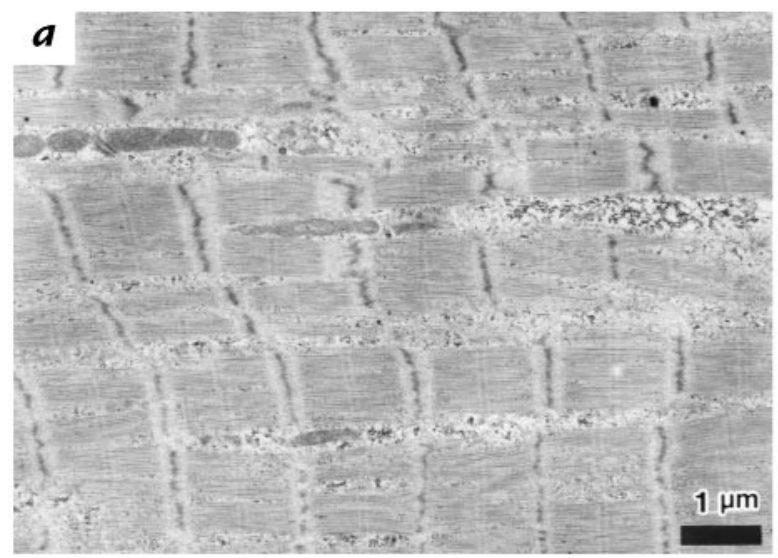

Figure 9 shows the expression of cardiomyocyte-specific transcription factors. Figure $9 a$ represents the RTPCR-Southern blot analysis of Nkx2.5/Csx, GATA4, and TEF-1 in CMG cells. Cardiomyocytes expressed GATA4, TEF-1, and Nkx2.5/Csx, whereas skeletal muscle cells only expressed TEF-1. Differentiated CMG myotubes expressed GATA4, TEF-1, and Nkx2.5/Csx. Figure $9 b$ represents the time course of GATA4, TEF-1, and Nkx2.5/Csx gene expressions in CMG cells. Interestingly, CMG cells already expressed these genes before 5-azacytidine treatment. Figure $9 c$ shows the time course of MEF-2A, MEF-2C, and MEF-2D gene expression. Because the primers were designed to demonstrate the alternative splicing forms of MEF- 2 genes, several bands could be observed. MEF-2C was already expressed before 5-azacytidine treatment, but MEF-2A and MEF-2D were induced after 5-azacytidine treatment.

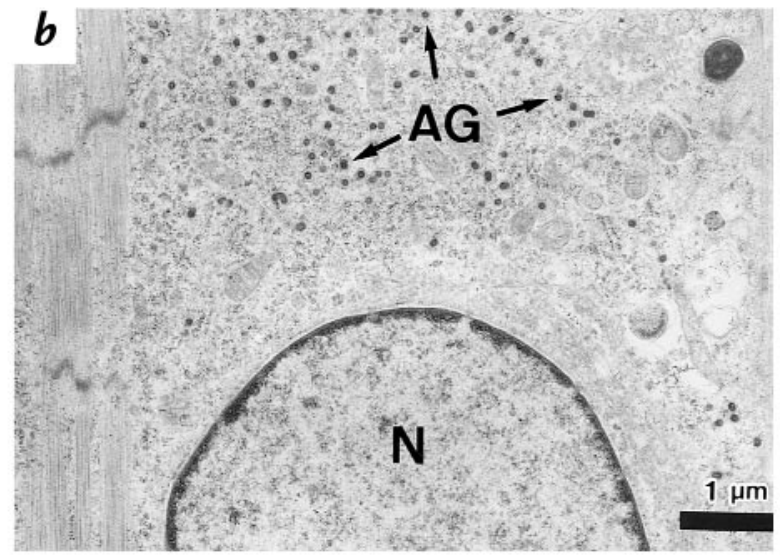

Figure 5

Transmission electron micrograph of CMG myotubes. (a) Differentiated CMG myotubes revealed well-organized sarcomeres. Rich glycogen granules and a number of mitochondria were observed. (b) Ultrastructural analysis revealed that nuclei $(N)$ were oval and positioned in the central part of the cell, not immediately beneath the sarcolemma. Atrial granules (AG), measuring 70-130 nm in diameter, are observed in the sarcoplasm and are concentrated especially in the juxtanuclear cytoplasm. Scale bars: $1 \mu \mathrm{m}$. 

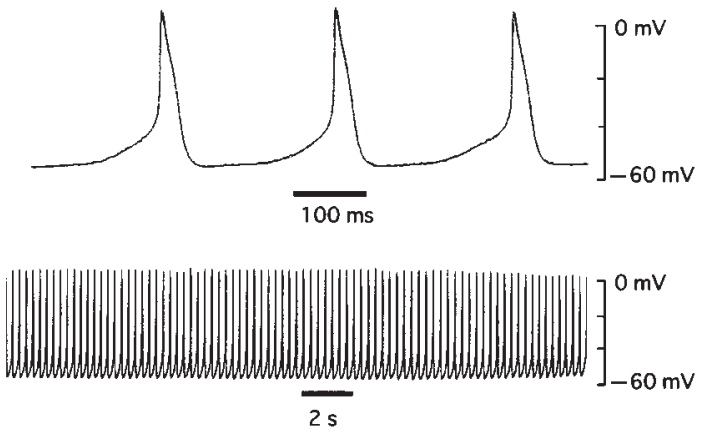

$b$

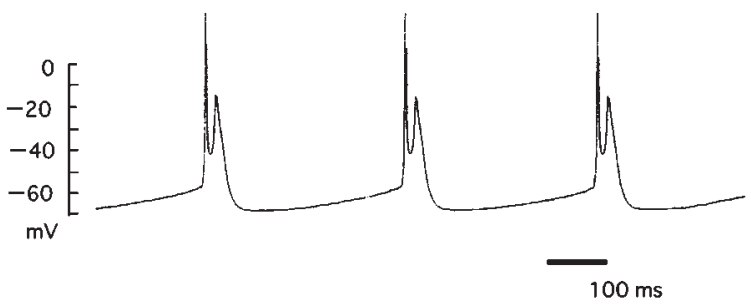

Figure 6

Representative tracing of the action potential of CMG myotubes. Action potential recordings using a conventional microelectrode were obtained from the spontaneously beating cells at day 28 after 5-azacytidine treatment. We categorized these action potentials into two groups: a sinus node-like action potential $(\boldsymbol{a})$ or a ventricular cardiomyocyte-like action potential $(\boldsymbol{b})$. These action potentials have a relatively shallow resting membrane potential with late diastolic slow depolarization: a pacemaker-like potential. The ventricular cardiomyocyte-like action potential had peak notch-plateau characteristics, with an initial tall overshoot in phase 0 , a repolarizing notch in phase 1 , and a second depolarizing plateau in phase 2, whereas the sinus node-like action potential had none of these features. Beating cycle length, action potential amplitude, action potential duration, and most diastolic potential are given in Table 2.

\section{Discussion}

We have established a cardiomyogenic cell line (CMG) from mouse bone marrow stromal cells that can be induced to differentiate into cardiomyocytes in vitro by 5 azacytidine treatment. A number of lines of evidence confirmed the cardiomyocyte characteristics of CMG cells. These cells expressed a number of cardiomyocyte-specific genes including ANP, BNP, GATA4, and Nkx2.5/Csx. In ventricular muscle of small mammals, there is a developmental switch from expression of $\beta-\mathrm{MHC}$, which is the predominant fetal form, to that of $\alpha$-MHC around the time of birth. There is also a developmental switch from expression of $\alpha$-skeletal actin, which is the predominant fetal and neonatal form, to that of $\alpha$-cardiac actin, the predominant adult form. Differentiated CMG cells mainly expressed $\beta$ MHC and $\alpha$-skeletal actin. Expression of $\alpha$-MHC and $\alpha$ cardiac actin was detected, but at low levels. MLC- 2 genes are specifically expressed in the chamber. MLC- $2 \mathrm{v}$ is specifically expressed in ventricular cells, whereas MLC-2a was specifically expressed in atrial cells. Differentiated CMG cells expressed MLC-2v, but not MLC-2a. Moreover, skeletal muscle cells do not express $\alpha-\mathrm{MHC}$ or MLC-2v. These results indicated that differentiated CMG cells had a phenotype specific to fetal ventricular cardiomyocytes.

Differentiated CMG cells expressed Nkx2.5/Csx, GATA4, TEF-1, and MEF-2C before final 5-azacytidine treatment.
The MEF-2A and MEF-2D genes were expressed after final 5 -azacytidine treatment. This pattern of gene expression in CMG cells was similar to that of in vivo developing cardiomyocytes (33). These results indicate that the stage of differentiation of the CMG cell is between cardiomyocyteprogenitor and differentiated cardiomyocytes.

Differentiated CMG cells connected to adjoining cells via intercalated discs, formed myotubes, and beat spontaneously. These differentiated CMG myotubes have a cardiomyocyte-like ultrastructure, including typical sarcomeres, a centrally positioned nucleus, abundant glycogen granules, a number of mitochondria, and many atrial granules. Tagoe et al. (34) reported that the most common size of atrial granules observed in the adult mice atrium was 150-200 $\mathrm{nm}$ in diameter, but they also found that $\sim 35 \%$ of the atrial granules in adult mice atria ranged between 50 and $150 \mathrm{~nm}$ in diameter. The atrial granules observed in the differentiated CMG myotubes were $70-130 \mathrm{~nm}$ in diameter. A previous report (35) found that almost all atrial myocytes expressed ANP in fetal heart, whereas in the ventricular wall, cells containing immunoreactive granules were scattered. Analysis of the pattern of expression of cardiomyocyte-specific genes indicated that the phenotype of the differentiated CMG cardiomyocytes corresponded to fetal ventricular cardiomyocytes. The high-density granules observed in the differentiated CMG cells might correspond to those in fetal ventricular cardiomyocytes.

CMG myotubes have either sinus node-like or ventricular myocyte-like action potentials with a relatively long action potential duration or plateau, a relatively shallow resting membrane potential, and a pacemakerlike late diastolic slow depolarization.

Although action potentials can be seen in noncardiomyocyte cells such as skeletal muscle cells or nerve cells, the action potential in CMG cells is characterized by duration (36-39). The duration of action potentials in

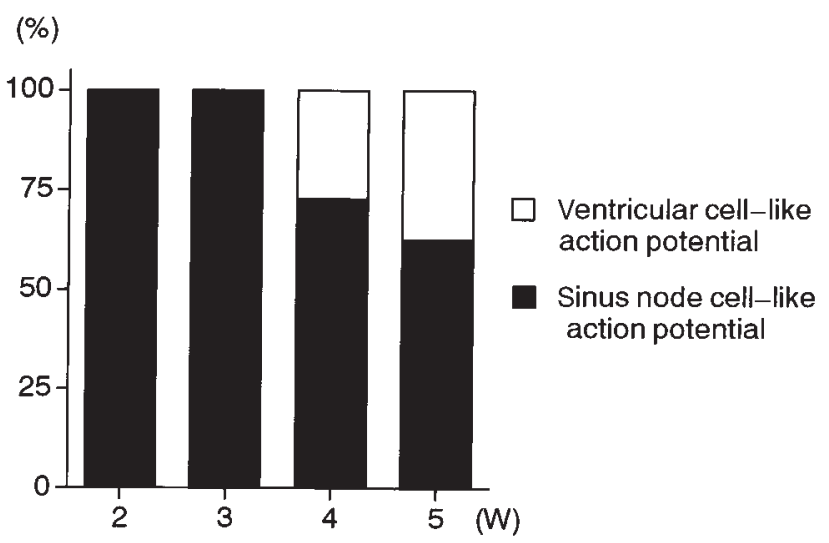

Time after 5-azacytidine treatment

\section{Figure 7}

Time course of the percentage of the pattern of action potentials in CMG myotubes. The percentage of the sinus node-like and ventricular cardiomyocyte-like action potential of the CMG cells after 5-azacytidine treatment was demonstrated. Ventricular cardiomyocyte-like action potential was first recorded 4 weeks after 5 -azacytidine treatment, and incidence rapidly increased thereafter. 

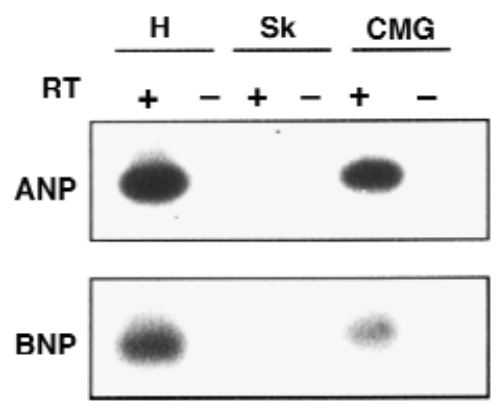

\section{$\boldsymbol{b}$}

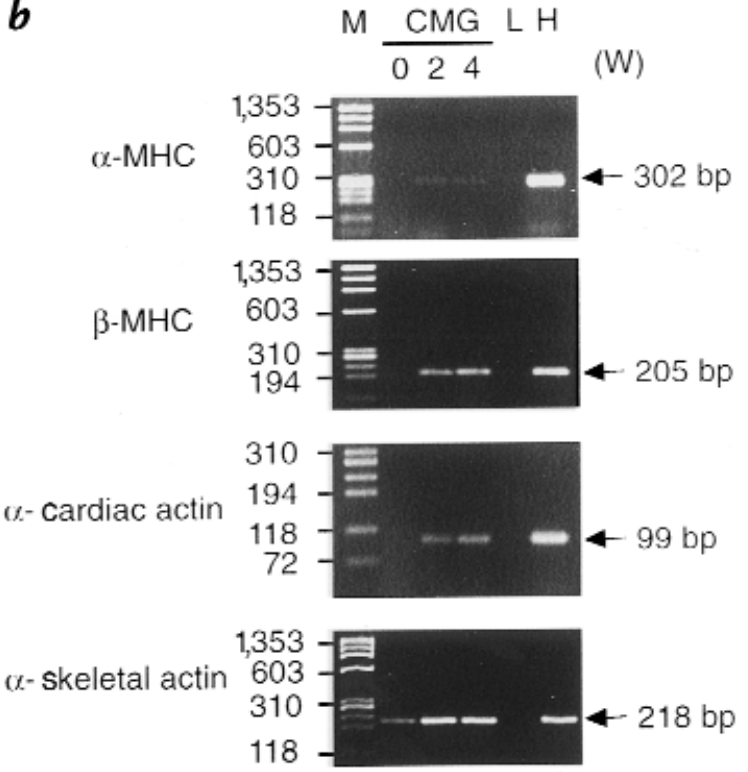

$\boldsymbol{C}$

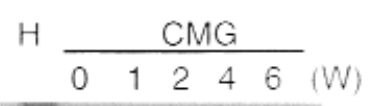

$\alpha$-cardiac actin

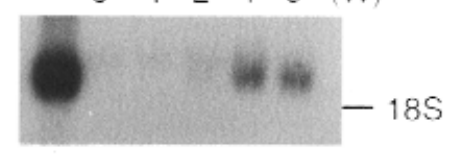

(1-skeletal actin

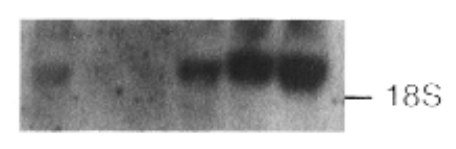

GAPDH

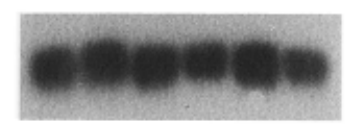

$d$
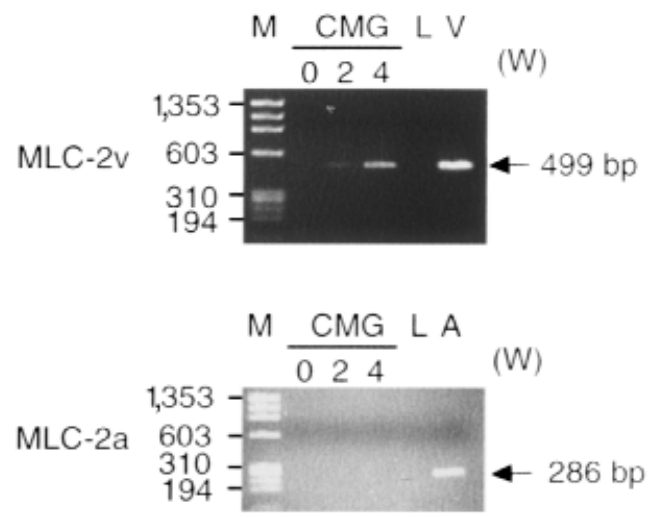

\section{Figure 8}

Expression of cardiomyocyte-specific genes in and phenotype analysis of CMG cells. (a) reverse transcriptase ( $R T)$-PCR Southern analysis of natriuretic peptide $(A N P)$ and brain natriuretic peptide $(B N P)$ in CMG cells. Total RNA was isolated from mouse heart $(H)$, skeletal muscle $(S k)$, and differentiated CMG cells. After DNase I treatment, RT-PCR was performed, as described in Methods, for ANP and BNP. Each PCR product was identified by Southern blot using ${ }^{32} \mathrm{P}$-labeled synthetic oligonucleotides. Both ANP and BNP are specifically expressed in cardiac muscle and CMG myotubes. (b) RT-PCR analysis of $\alpha$-myosin heavy chain $(\alpha-M H C)$, $\beta$-myosin heavy chain $(\beta-M H C), \alpha$-cardiac actin, and $\alpha$-skeletal actin expression in CMG cells. Heart $(H)$ and liver $(L)$ were used as positive and negative controls. $M$ represents $\Phi X$ Xaelll molecular size marker. CMG myotubes expressed both $\alpha$-cardiac actin and $\alpha$-skeletal actin, but the expression of $\alpha$-skeletal actin was much stronger than that of $\alpha$-cardiac actin. Note that $\alpha$-skeletal actin expression was observed before the final 5 -azacytidine treatment, although expression was weak. CMG myotubes expressed both $\alpha$ - and $\beta$-MHC, but the expression of $\beta$-MHC was much stronger than that of $\alpha$-MHC. (c) Northern blot analysis of $\alpha$-cardiac actin and $\alpha$-skeletal actin expression in CMG cells. Adult heart $(H)$ was used as a positive control. $\alpha$-cardiac actin was more abundantly expressed in adult heart. On the other hand, $\alpha$-skeletal actin was more abundantly expressed in CMG cells. Glyceraldehyde-3-phosphate dehydrogenase (GAPDH) was used as a loading internal control. (d) RT-PCR analysis of MLC-2a and $2 v$ expression in CMG cells. Adult atrial muscle $(A)$ was used as a positive control for MLC-2a, and adult ventricular muscle ( $V$ ) was used as a positive control for MLC-2v. M represents $\Phi$ XHaell molecular size marker. CMG myotubes expressed MLC-2v, but not MLC-2a. These patterns of gene expression in the CMG myotubes corresponded to the phenotype specific to fetal ventricular cardiomyocytes.

skeletal muscle cells or nerve cells are $<5 \mathrm{~ms}(40,41)$. The most diastolic potential, action potential amplitude, and the overshoot potential of the sinus node-like CMG cells were close to the equivalent values reported in vivo rabbit sinus node cells (42). In rabbit ventricular cells, the most diastolic potential and action potential amplitude were reported to be approximately between -90 and $-95 \mathrm{mV}$, and $120 \mathrm{mV}$, respectively. Although the most diastolic potential and action potential amplitude of the ventricular cardiomyocyte-like CMG cells were slightly shorter than these values, the shape of the action potential was very close to in vivo ventricular cardiomyocyte. The observation of several distinctive patterns of action potential in CMG cells may reflect different developmental stages. The electrophysiological patterns of action potential and expression patterns of the ion channels in differentiated CMG cells should be clarified in the future.

Both embryonic stem (ES) cells (43) and embryonal carcinoma (EC) cells $(44,45)$ may differentiate into cardiomyocytes in vitro. These cells were derived from totipotent embryonal blastocyst and either required endoderm for mesodermal differentiation or could differentiate into endoderm and ectoderm by themselves. CMG cells differ from these cells in several ways. First, CMG cells were obtained from adult bone marrow. Second, they did not require endoderm for differentiation, and they only differentiated into mesoderm, as demonstrated in other marrow stromal cell lines. Third, CMG cells were easy to culture because they are adherent like fibroblasts, have a high growth rate, and do not require expensive cytokine (leukemia inhibitory factor) supplement. Finally, differentiation is easily induced by 5 -azacytidine treatment. ES cells 
a
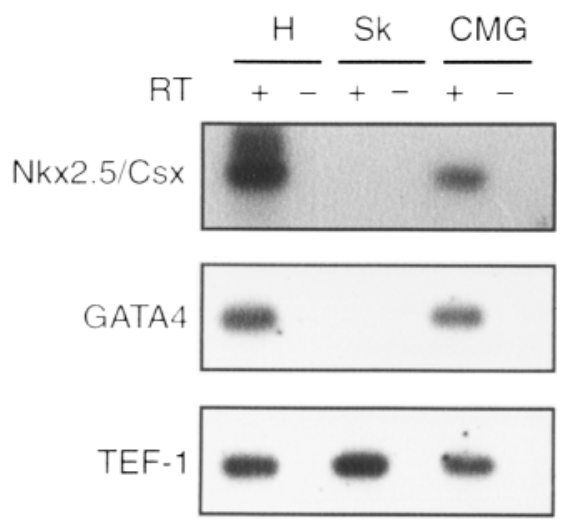

C

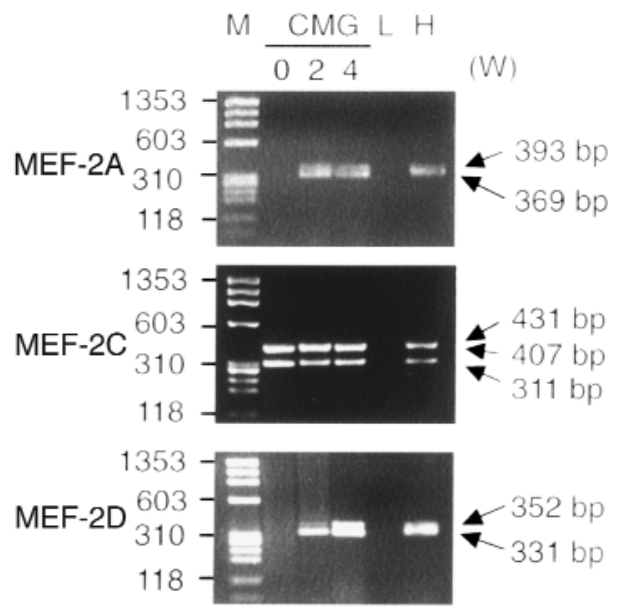

and EC cells differentiate into cardiomyocytes at rates of $\sim 50 \%$ and $5 \%$, respectively. CMG cells differentiate into cardiomyocyte-like cells after final 5-azacytidine treatment, and the efficiency of the differentiation into cardiomyocytes is $\sim 30 \%$. Thus, CMG cells provide a powerful tool for the further investigation of cardiomyocyte differentiation. Although transcription factors such as d-HAND, e-HAND (46), MEF-2C (33, 47), Nkx2.5/Csx, GATA4, and TEF-1 are known to play important roles in cardiac development (48), the lack of a model for cardiomyocyte differentiation has meant that little is known about the interactions of these genes. This simple new model for cardiomyogenesis may help clarify the cascade of transcriptional activation that regulates differentiation into cardiomyocytes.

\section{Acknowledgments}

We thank Makoto Suematsu for help with video recording of CMG myotube contraction and Naomichi Yagi for the ultrastructural examination. The authors also acknowledge Yoshiko Kurokawa and Rie Inaba for technical assistance. This study was supported in part by research grants of "Research for the Future" Program from the Japan Society for the Promotion of Science (JSPS-RFTF97I00201); the Ministry of Education, Science and Culture of Japan; the Ministry of Welfare of Japan; and the Japan Owner's Association.

1. Weintraub, H. 1993. The MyoD family and myogenesis: redundancy, networks, and thresholds. Cell. 75:1241-1244.

2. Silberstein, L., Webster, S.G., Travis, M., and Blau, H.M. 1986. Developmental progression of myosin gene expression in cultured muscle cells. Cell. 46:1075-1081.

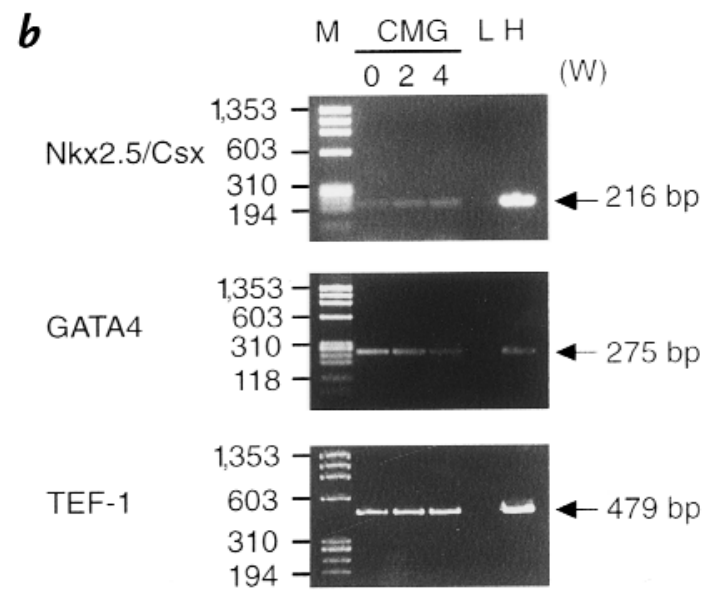

Figure 9

RT-PCR analysis of cardiomyocyte-specific transcription factors. (a) Reverse transcriptase (RT)-PCR Southern blot of Nkx2.5/Csx, GATA4, and TEF-1 in differentiated CMG myotubes. Heart $(H)$ and skeletal muscles (Sk) were used as controls. Cardiomyocytes expressed GATA4, TEF-1, and Nkx2.5/Csx, whereas skeletal muscle cells (Sk) only expressed TEF-1. Differentiated CMG myotubes expressed GATA4, TEF-1, and Nkx2.5/Csx. (b) Time course of the expression of Nkx2.5/Csx, GATA4, and TEF-1. CMG cells already expressed these genes before 5-azacytidine treatment. Heart $(H)$ and liver $(L)$ were used as positive and negative controls. $M$ represents ФXHaell molecular size marker. (c) Time course of the expression of MEF$2 \mathrm{~A},-2 \mathrm{C}$, and $-2 \mathrm{D}$ genes in CMG cells. Because the primers were designed to demonstrate the alternative splicing forms MEF-2 genes, several bands can be observed. CMG cells expressed the MEF-2C gene before 5-azacytidine treatment, whereas MEF-2A and MEF-2D gene expression was observed after 5-azacytidine treatment.

3. Olson, E.N., and Srivastava, D. 1996. Molecular pathways controlling heart development. Science. 272:671-676.

4. Lassar, A.B., Paterson, B.M., and Weintraub, H. 1986. Transfection of a DNA locus that mediates the conversion of $10 \mathrm{~T} 1 / 2$ fibroblasts to myoblasts. Cell. 47:649-656.

5. Taylor, S.M., and Jones, P.A. 1979. Multiple new phenotypes induced in $10 \mathrm{~T} 1 / 2$ and $3 \mathrm{~T} 3$ cells treated with 5-azacytidine. Cell. 17:771-779.

6. Murry, C.E., Wiseman, R.W., Schwartz, S.M., and Hauschka., S.D. 1996. Skeletal myoblast transplantation for repair of myocardial necrosis. $J$. Clin. Invest. 98:2512-2523.

7. Rhodes, S.J., and Konieczny, S.F. 1989. Identification of MRF4: a new member of the muscle regulatory factor gene family. Genes Dev. 3:2050-2061.

8. Wright, W.E., Sassoon, D.A., and Lin, V.K. 1989. Myogenin, a factor regulating myogenesis, has a domain homologous to MyoD. Cell. 56:607-617.

9. Braun, T., Winter, B., Bober, E., and Arnold, H.H. 1990. Transcriptional activation domain of the muscle-specific gene-regulatory protein myf5. Nature. 346:663-665.

10. Rawls, A., and Olson, E.N. 1997. MyoD meets its maker. Cell. 89:5-8.

11. Fishman, M.C., and Chien, K.R. 1997. Fashioning the vertebrate heart: earliest embryonic decisions. Development. 124:2099-2117.

12. Kodama, H., et al. 1997. Leukemia inhibitory factor, a potent cardiac hypertrophic cytokine, activates the JAK/STAT pathway in rat cardiomyocytes. Circ. Res. 81:656-663.

13. Pan, J., et al. 1997. Role of angiotensin II in activation of the JAK/STAT pathway induced by acute pressure overload in the rat heart. Circ. Res. 81:611-617.

14. Leor, J., Patterson, M., Quinones, M.J., Kedes, L.H., and Kloner, R.A. 1996. Transplantation of fetal myocardial tissue into the infarcted myocardium of rat. A potential method for repair of infarcted myocardium? Circulation. 94(Suppl. II):332-336.

15. Li, R.K., et al. 1997. Natural history of fetal rat cardiomyocytes transplanted into adult rat myocardial scar tissue. Circulation. 96(Suppl. II):179-186.

16. Soonpaa, M.H., Koh, G.Y., Klug, M.G., and Field, L.J. 1994. Formation of nascent intercalated disks between grafted fetal cardiomyocytes and host myocardium. Science. 264:98-101.

17. Delcarpio, J.B., and Claycomb, W.C. 1995. Cardiomyocyte transfer into 
the mammalian heart. Cell-to-cell interactions in vivo and in vitro. Ann. NY Acad. Sci. 752:267-285

18. Prockop, D.J. 1997. Marrow stromal cells as stem cells for nonhematopoietic tissues. Science. 276:71-74.

19. Rickard, D.J., Sullivan, T.A., Shenker, B.J., Leboy, P.S., and Kazhdan, I. 1994. Induction of rapid osteoblast differentiation in rat bone marrow stromal cell cultures by dexamethasone and BMP-2. Dev. Biol. 161:218-228.

20. Friedenstein, A.J., Chailakhyan, R.K., and Gerasimov, U.V. 1987. Bone marrow osteogenic stem cells: in vitro cultivation and transplantation in diffusion chambers. Cell Tissue Kinet. 20:263-272.

21. Ferrari, G., et al. 1998. Muscle regeneration by bone marrow-derived myogenic progenitors. Science. 279:1528-1530.

22. Umezawa, A., et al. 1992. Multipotent marrow stromal cell line is able to induce hematopoiesis in vivo. J. Cell. Physiol. 151:197-205.

23. Ashton, B.A., et al. 1980. Formation of bone and cartilage by marrow stromal cells in diffusion chambers in vivo. Clin. Orthop. 151:294-307.

24. Dexter, T.M., Allen, T.D., and Lajtha, L.G. 1977. Conditions controlling the proliferation of haemopoietic stem cells in vitro. J. Cell Physiol. 91:335-344.

25. Seidman, C.E., Bloch, K.D., Klein, K.A., Smith, J.A., and Seidman, J.G. 1984. Nucleotide sequences of the human and mouse atrial natriuretic factor genes. Science. 226:1206-1209.

26. Sudoh, T., Kangawa, K., Minamino, N., and Matsuo, H. 1988. A new natriuretic peptide in porcine brain. Nature. 332:78-81.

27. Robbins, J., Gulick, J., Sanchez, A., Howles, P., and Doetschman, T. 1990 Mouse embryonic stem cells express the cardiac myosin heavy chain genes during development in vitro. J. Biol. Chem. 265:11905-11909.

28 Kubalak, S.W., Miller-Hance, W.C., O'Brien, T.X., Dyson, E., and Chien, K.R. 1994. Chamber specification of atrial myosin light chain-2 expression precedes septation during murine cardiogenesis. J. Biol. Chem. 269:16961-16970.

29. Komuro, I., and Izumo, S. 1993. Csx: a murine homeobox-containing gene specifically expressed in the developing heart. Proc. Natl. Acad. Sci. USA. 90:8145-8149.

30. Lints, T.J., Parsons, L.M., Hartley, L., Lyons, I., and Harvey, R.P. 1993. Nkx-2.5: a novel murine homeobox gene expressed in early heart progenitor cells and their myogenic descendants. Development. 119:419-431.

31. Arceci, R.J., King, A.A., Simon, M.C., Orkin, S.H., and Wilson, D.B. 1993 Mouse GATA-4: a retinoic acid-inducible GATA-binding transcription factor expressed in endodermally derived tissues and heart. Mol. Cell. Biol. 13:2235-2246.

32. Chen, Z., Friedrich, G.A., and Soriano, P. 1994. Transcriptional enhancer factor 1 disruption by a retroviral gene trap leads to heart defects and embryonic lethality in mice. Genes Dev. 8:2293-2301.

33. Edmondson, D.G., Lyons, G.E., Martin, J.F., and Olson, E.N. 1994. Mef2 gene expression marks the cardiac and skeletal muscle lineages during mouse embryogenesis. Development. 120:1251-1263.

34. Tagoe, C.N., Ayettey, A.S., and Yates, R.D. 1993. Comparative ultrastructural morphometric analysis of atrial specific granules in the bat, mouse, and rat. Anat. Rec. 235:87-94.

35. Venance, S.L., and Pang, S.C. 1989. Ultrastructure of atrial and ventricular myocytes of newborn rats: evidence for the existence of specific atrial granule-like organelles in the ventricle. Histol. Histopathol. 4:325-333.

36. Irisawa, H. 1989. Electrophysiology and contractile function. In Isolated adult cardiomyocytes. H.M. Piper and G. Isenberg, editors. CRC Press. Boca Raton, FL. 1-11.

37. Hoffman, B.F., and Cranefield, P.F. 1976. Electrophysiology of the heart. McGraw-Hill. New York, NY. 75-131.

38. Carmeliet, E. 1978. Cardiac transmembrane potentials and metabolism. Circ. Res. 42:577-587.

39. Draper, M.H., and Weidman, S. 1951. Cardiac resting and action potentials recorded with an intracellular electrode. J. Physiol. 115:74-94.

40. Nicholls, J.G., Martin, A.R., and Wallace, B.G. 1992. In From neuron to brain: a cellular and molecular approach to the function of the nervous system. $3 \mathrm{rd}$ ed. J.G. Nicholls, A.R. Martin, and B.G. Wallace, editors. Sinauer Associates. Sunderland, MA. 90-120.

41. Brinley, F.J., Jr. 1980. Excitation and conduction in nerve fibers. In Medical physiology. 14th ed. V.B. Mountcastle, et al., editors. Mosby. St. Louis, MO. 46-81.

42. Noma, A., and Irisawa, H. 1976. Membrane currents in the rabbit sinoatrial node cell as studied by the double microelectrode method. Pflugers Arch. 364:45-52.

43. Doetschman, T.C., Eistetter, H., Katz, M., Schmidt, W., and Kemler, R. 1985. The in vitro development of blastocyst-derived embryonic stem cell lines: formation of visceral yolk sac, blood islands and myocardium. $J$. Embryol. Exp. Morphol. 87:27-45.

44. McBurney, M.W., Jones-Villeneuve, E.M., Edwards, M.K., and Anderson, P.J. 1982. Control of muscle and neuronal differentiation in a cultured embryonal carcinoma cell line. Nature. 299:165-167.

45. Jones-Villeneuve, E.M., McBurney, M.W., Rogers, K.A., and Kalnins, V.I. 1982. Retinoic acid induces embryonal carcinoma cells to differentiate into neurons and glial cells. J. Cell Biol. 94:253-262.

46. Srivastava, D., Cserjesi, P., and Olson, E.N. 1995. A subclass of bHLH proteins required for cardiac morphogenesis. Cell. 56:607-617.

47. Lin, Q., Schwarz, J., Bucana, C., and Olson, E.N. 1997. Control of mouse cardiac morphogenesis and myogenesis by transcription factor MEF2C. Science. 276:1404-1407.

48. Harvey, R.P. 1996. NK-2 homeobox genes and heart development. Dev. Biol. 178:203-216. 